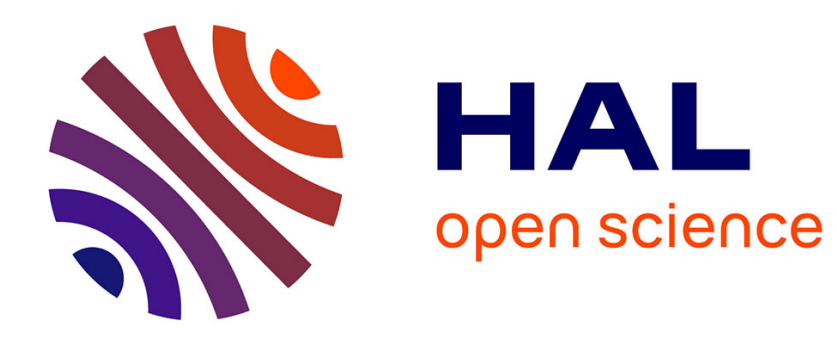

\title{
Group selection: The quest for social preferences
}

Marcus Salomonsson

\section{To cite this version:}

Marcus Salomonsson. Group selection: The quest for social preferences. Journal of Theoretical Biology, 2010, 264 (3), pp.737. 10.1016/j.jtbi.2010.02.035 . hal-00591229

\section{HAL Id: hal-00591229 https://hal.science/hal-00591229}

Submitted on 8 May 2011

HAL is a multi-disciplinary open access archive for the deposit and dissemination of scientific research documents, whether they are published or not. The documents may come from teaching and research institutions in France or abroad, or from public or private research centers.
L'archive ouverte pluridisciplinaire HAL, est destinée au dépôt et à la diffusion de documents scientifiques de niveau recherche, publiés ou non, émanant des établissements d'enseignement et de recherche français ou étrangers, des laboratoires publics ou privés. 


\section{Author's Accepted Manuscript}

Group selection: The quest for social preferences

Marcus Salomonsson

PII:

S0022-5193(10)00110-4

DOI: doi:10.1016/j.jtbi.2010.02.035

Reference: YJTBI 5888

To appear in:

Journal of Theoretical Biology

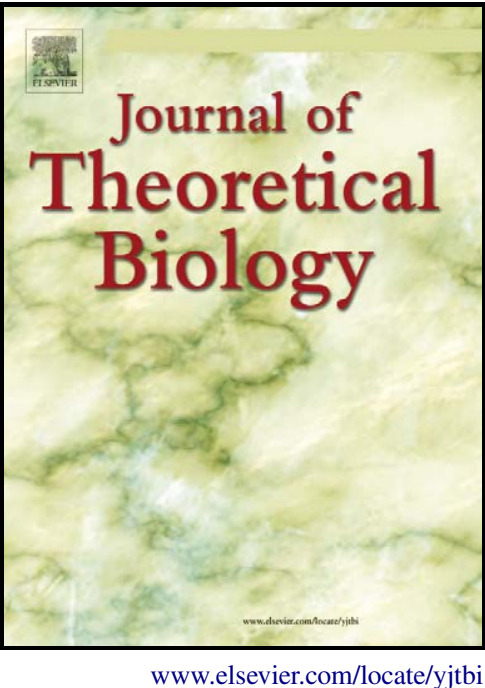

Received date: 28 April 2009

Revised date: $\quad 29$ December 2009

Accepted date: 20 February 2010

Cite this article as: Marcus Salomonsson, Group selection: The quest for social preferences, Journal of Theoretical Biology, doi:10.1016/j.jtbi.2010.02.035

This is a PDF file of an unedited manuscript that has been accepted for publication. As a service to our customers we are providing this early version of the manuscript. The manuscript will undergo copyediting, typesetting, and review of the resulting galley proof before it is published in its final citable form. Please note that during the production process errors may be discovered which could affect the content, and all legal disclaimers that apply to the journal pertain. 


\title{
GROUP SELECTION: THE QUEST FOR SOCIAL PREFERENCES
}

\author{
MarCus SALOMONSSON* \\ Stockholm School of Economics
}

December 29, 2009

\begin{abstract}
This paper surveys the literature on group selection. I describe the early contributions and the group selection controversy. I also describe the main approaches to group selection in the recent literature; fixation, assortative group formation, and reproductive externalities.
\end{abstract}

Keywords: Altruism; spite; externalities; conformity; fixation; signalling

JEL Classification: C70; D03; D62; D64

\section{Contents}

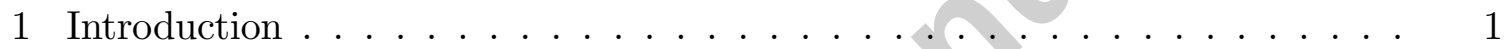

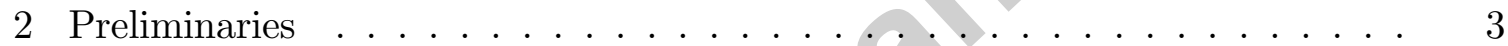

3 Early contributions . . . . . . . . . . . . ...... 5

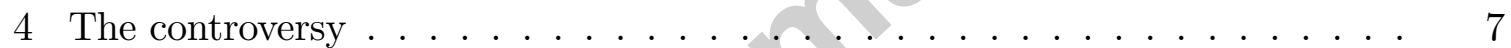

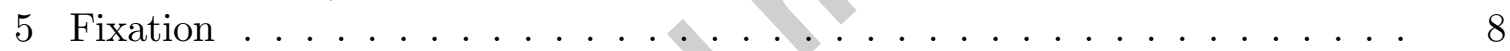

6 Assortative group formation . . . . . . . . . . . . . . . 9

7 Reproductive externalities . . . . . . . . . . . . . . . . . 13

8 Group selection or kin selection . . . . . . . . . . . . . . 16

9 Conclusion . . . . . . . . . . . . . . . . . . 17

\section{INTRODUCTION}

Individual selection has been extremely powerful in explaining both human and animal behavior. However, both empirical and experimental studies have found evidence that humans and animals to some degree have social preferences (Dawes and Thaler, 1988; Ledyard, 1995; Gintis et al, 2003). Several mechanisms to foster social preferences have been advanced in the literature. Nowak (2006) discusses five of them (see also Leimar and Hammerstein, 2006). They are kin selection, direct and indirect reciprocity, networks, ${ }^{1}$ and group selection. All five mechanisms, at least in their modern forms, are within the selfish paradigm. They all amount to saying that an organism may appear

\footnotetext{
*I am grateful to the Wallenberg Foundation for financial support. I am also grateful for comments from Cédric Argenton, Christoph Kuzmics, Olof Leimar, Erik Mohlin, Arne Traulsen, Fernando VegaRedondo, Jörgen Weibull, and three anonymous reviewers. Any errors are my own.

${ }^{1}$ Nowak uses the term network reciprocity. I will instead only call these models network models, to emphasize that repeated interactions are not needed. These models are also called spatial models. Nowak argues that the more general term network is better suited.
} 
to have social preferences, but that these preferences can be explained by appealing to selfishness. Regardless of how social preferences have been selected for, it should be noted that they are probably not calibrated for all conceivable situations. Instead, they should rather be suited for situations that are, or have been, common to the organism. In fact, to preserve resources, preferences may not even be perfectly tuned for such situations. It may be more economical to have rule of thumb preferences. For example, a predisposition towards cooperation is not always beneficial. However, in most cases it may be. If the predisposition is not sufficiently costly, compared to the resources saved, it may be preserved. Thus, in a broader sense, when resources are taken into account, the preferences may still be optimal.

Kin selection was formally analyzed by Hamilton (1964). The idea, popularized by Dawkins (1976), is that organisms are vehicles for genes to spread. Genes thus have selfish reasons to influence their organism into helping other organisms with the same gene. This implies that it is rational for parents to help their offspring, and for siblings to help each other etc. The principle is illustrated by Haldane's famous quote that he would sacrifice his life for "two brothers or eight cousins".

Direct and indirect reciprocity concern repeated interactions. Direct reciprocity, advanced by Trivers (1971), refers to a situation where these interactions take place between the same individuals. Indirect reciprocity instead refers to situations where the interactions take place between new individuals but where each individual has a reputation acquired through earlier interactions. In game theory direct and indirect reciprocity are often treated as variants of the Folk theorems, formally analyzed by Aumann (1959), Friedman (1971), Rubinstein (1979), and Fudenberg and Maskin (1986). The Folk theorems imply that if a Prisoner's Dilemma is repeated indefinitely, and with a sufficiently high discount factor, then there exists several subgame perfect Nash equilibria, some of which consist of cooperation in every period.

Network models build on the idea that if individuals interact locally, then it is possible for altruists to group together, so that they mainly confer benefits on each other (see Eshel et al, 1998; Ellison, 1993; Ohtsuki and Nowak, 2006).

Group selection also involves interactions in smaller clusters, however, there is more to it than just a local interaction. There is also some kind of competition between groups. In this survey I will consider three basic approaches to group selection. The first approach is the fixation approach, where the crucial element is the existence of pure groups. The second approach is the assortative group formation approach, where there is a correlation between being a certain type and being matched with others of that type. The third approach is the reproductive externalities approach, where group competition makes it possible to internalize externalities. The term externality is widely used in economics, whereas the term by-product is often used in biology. An externality is a side effect of an action. The side effect is also inconsequential to the initiator of the action. If an externality is internalized, then the initiator of the action is made to take into account the side effect.

The paper is organized as follows. First I discuss two symmetric $2 \times 2$-games Coordination Games and Prisoner's Dilemma games - where group selection is especially relevant. Group selection may of course also be relevant for more complex games, but these games illustrate neatly the two issues that group selection can address. The first 
issue is the problem of equilibrium selection: If there are several equilibria, can group selection tell us anything about which equilibrium will be played? The second issue is the problem of social preferences: Can group selection lead to locally altruistic behavior being viable? After going through the games and briefly discussing the main arguments of the various approaches, I go on and describe the early literature on group selection, up to the group selection controversy. Then I consider the more recent literature, and consider the three main approaches to group selection that have been formally explored. I then discuss the recent literature on the distinction between group selection and kin selection. Finally, I conclude.

I can unfortunately not claim to have covered all papers treating group selection. For other surveys of the vast group selection literature, see Sober and Wilson (1998), Bergstrom (2002), and chapter 6 in Okasha (2006). Dugatkin (2002) and Henrich (2004) also have extensive discussions of the concept.

\section{Preliminaries}

To fix ideas, let us consider two symmetric $2 \times 2$ games where group selection is of special interest (see Weibull, 1995 for a complete categorization of symmetric $2 \times 2$-games). Originally, the payoffs in these games were considered to be von Neumann-Morgenstern utilities, and still generally are. However, here we interpret the payoffs as fitness, typically the number of offspring.

The general formulation of symmetric $2 \times 2$ games is given by the payoff matrix

\begin{tabular}{|c|c|c|}
\hline & $A$ & $B$ \\
\hline$A$ & $\pi_{A A}$ & $\pi_{A B}$ \\
\hline$B$ & $\pi_{B A}$ & $\pi_{B B}$ \\
\hline
\end{tabular}

2.1. Coordination Games. The game (1) is a Coordination Game if $\pi_{A A}-\pi_{B A}>$ 0 and $\pi_{B B}-\pi_{A B}>0$. In this class of games there are two Nash equilibria in pure strategies. One pure Nash equilibrium is for both players to play $A$. The other pure equilibrium is for both players to play $B$. In generic games, i.e. games without any payoff ties, the two equilibria yield different payoffs.

In evolutionary settings, we often think of a large population. We randomly draw two individuals from the population and let them play the game against each other. The payoffs are then the offspring that the individuals get. Thus, if sufficiently many in the population play $A$, then individuals playing $A$ will get a higher payoff than individuals playing $B$. Thus, everybody playing $A$ can be an equilibrium outcome even if the equilibrium where everybody plays $B$ yields more.

Potentially, a group selection model could eliminate the low-yield equilibrium. A very basic model would be to randomly divide the population into groups, and then randomly draw two individuals from each group and let them play a Coordination Game. The individuals and their offspring are then returned to the group they came from. If the population is large and groups are formed randomly, then some groups will converge to the high-yield equilibrium while others will converge to the low-yield equilibrium. Since individuals in the groups that converge to the high-yield equilibrium earn more, they will outgrow the individuals in the low-yield groups. 
This sketchy model is in fact only a network model. There is a group structure, but no group selection. However, if we would dissolve groups at some probability - and let them be replaced by new groups formed by individuals from high yielding groups - then we effectively have a group selection model. Canals and Vega-Redondo (1998) have constructed such a model. They consider a subset of Coordination Games, called Stag Hunt games. The game (1) is a Stag Hunt game if the high yield equilibrium, also called the Pareto dominant equilibrium, is not the risk dominant equilibrium.

Intuitively one can think of the risk dominant equilibrium in the following way: Imagine that player 1 has no idea what player 2 will play, and thus assumes that he will play $A$ or $B$ with equal probability. If then player 1 would achieve a higher expected payoff by playing $B$, then both players playing $B$ would be the risk dominant equilibrium. Another way of understanding the concept is to say that the risk dominant equilibrium has the largest basin of attraction.

In two very influential papers, Kandori, Mailath, and Rob (1993) and Young (1993) showed that, in a standard one-population setting with mutations, the population would spend most of its time close to the risk dominant equilibrium (also see Antal et al, 2009). The reason is that fewer mutations are needed for a population to shift from the Pareto optimal basin of attraction to the risk dominant basin of attraction than vice versa. As a result, a population process with mutations would spend most of its time close to the risk dominant equilibrium. Since there is no group selection in a network model, this will also be the case in these models, as demonstrated by Ellison (1993). Indeed Ellison showed that convergence to the risk dominant equilibrium will be faster in a network model.

However, in a group selection model, the result may be completely different. Groups in the Pareto optimal equilibrium would spread faster than groups in the risk dominant equilibrium. This may compensate for the fact that mutations are more likely to take the group from the Pareto optimal equilibrium to the risk dominant equilibrium, rather than the other way around. As we will see, Canals and Vega-Redondo (1998) show that this is indeed the case when the mutation rate approaches zero. One could also assume that individuals would migrate from low yielding to high yielding groups, which would favor the Pareto optimal equilibrium rather than the risk dominant equilibrium. Oechssler (1997), Ely (2002), and Kuzmics (2003) have shown that this is the case.

2.2. Prisoner's Dilemma games. In this class of games, group selection has been more controversial. The game (1) is a Prisoner's Dilemma game if $\pi_{A A}-\pi_{B A}<0$, $\pi_{B B}-\pi_{A B}>0$, and $\pi_{A A}>\pi_{B B}$. Here both players will play $B$ in equilibrium, despite the fact that if they could commit to playing $A$, they would both earn more.

The strategy $A$ is often referred to as an altruistic strategy. The reason is that by playing $A$ a player confers a benefit on the other player while inflicting harm on himself. Players playing $A$ is often referred to as cooperators, while players playing $B$ is often referred to as deviators.

A network model in this context would again be to divide the population into groups. Again high-yield groups, i.e. those with many altruists, should grow faster than lowyield groups. However, now the situation is different compared to the Coordination Games. Within each group the best response is to defect. This means that although 
groups with many altruists may earn more than other groups, each altruist will earn less than a defector in his group. As a result, in the long run the population should converge to everybody defecting.

A theoretical possibility to avoid such an outcome is if neither migration nor mutations are allowed and all players in at last one group play the pure strategy $A$. Then that group will grow much faster than the other groups and eventually overtake them. Although such models are really network models, they have historically been called group selection models or Haystack models. To somewhat adhere to this tradition I will call them group selection models based on fixation.

Yet another example of a network model often presented as a group selection model is what I will call group selection models based on assortative group formation. In these models there is again no actual competition between groups, but rather a correlation between playing $A$ and ending up in groups where others also play $A$.

An easy way to extend a network model into a group selection model is to assume that groups are wiped out - with everybody in the group receiving the payoff 0 - with a probability negatively dependent on the sum of payoffs in the group. For example, consider groups of two players and the following Prisoner's Dilemma

\begin{tabular}{|c|c|c|}
\hline & $A$ & $B$ \\
\hline$A$ & 4 & 2 \\
\hline$B$ & 5 & 3 \\
\hline
\end{tabular}

Suppose that groups with only cooperators never are wiped out, whereas mixed groups are wiped out with the probability 0.5 , and defecting groups always are wiped out. Then the expected profit of a cooperator in a pure group is 4 , whereas it is 1 in mixed groups. The expected profit of a defector is 2.5 in mixed groups and 0 in pure groups. If we start off with an equal proportion of cooperators and defectors in the population, and group formation is completely random, then a player has an equal probability of ending up in a pure group or a mixed group. As a result, a cooperator's expected payoff is 2.5, while a defector's expected payoff is 1.25 . Thus, a cooperator has a higher expected payoff than a defector. Models of this type will be called group selection models based on reproductive externalities.

Before we turn to these three approaches to group selection I will briefly discuss the early group selection literature and the group selection controversy.

\section{EARLY CONTRIBUtions}

Fittingly, it was Darwin who made the first allusion to group selection in The Descent of Man and Selection in Relation to Sex. The following sentence is often quoted:

"There can be no doubt that a tribe including many members who, from possessing in a high degree the spirit of patriotism, fidelity, obedience, courage, and sympathy, were always ready to give aid to each other and to sacrifice themselves for the common good, would be victorious over most other tribes, and this would be natural selection." (Darwin (1871), page 166.) 
Thus, Darwin saw that social preferences could be developed through natural selection. In addition he seems to have held the view that it was some form of competition between groups that would foster these social preferences.

Carr-Saunders (1922) thought that group selection fostered social evolution only among humans. He argued that it came about in primitive societies. These societies were nominally thought to be nomad societies, but Carr-Saunders argued that they were in fact restricted to a territory, within which they evolved social conventions to optimize the potential for long-term survival. Through abstention, abortion, and infanticide, they restricted their numbers so that an optimum number was reached. At this number of individuals, the income per head was maximized. These social conventions served to avoid more Malthusian methods of population control, the objective being to avoid social instability. A high variability implies a higher risk of going extinct (see for example the discussion in Williams, 1966).

Among the early contributions, Wright (1945), was the only one to construct a mathematical model. The aim was to show that a "character of value to the population, but disadvantageous at any given moment to the individual" could survive. He noted that if such a character - or strategy in game theoretical terminology - completely dominated a group, then that group would grow much faster than other groups. However, if a selfish strategy appeared in the group - either by mutation or migration - it would take over the group and the altruistic strategy would disappear.

Wright thus noted that isolation and fixation of the group was necessary for an altruistic trait to be preserved. His idea seems to be based on several groups that are isolated for long times. He argued that drift - i.e. random occurrences in reproduction could lead to complete domination of altruists in a group. Once fixation had occurred, there would be no way for the selfish trait to reappear in the group, barring mutations and migration. The group would then reproduce much faster than other groups. Eventually, after a long period of isolation, a migration phase would ensue. The group would then spread over the world and a new phase of isolation would follow. A group would eventually drift into fixation, and the cycle would restart.

By stressing isolation and fixation, and the trade-off between migrating altruists and resident egoists, Wright anticipated the haystack model of Maynard Smith (1964). The main conceptual difference is that, as we will see, Maynard Smith considered group formation to be the phase where the altruists had the largest chance of completely dominating a group.

Wynne-Edwards (1962), somewhat like Carr-Saunders (1922), was concerned with the problem of resource management. In particular he wanted to construct a theory to explain how a species, or a group from a species, managed resources to avoid extinction. He drew the parallel to the North Pacific Sealing Convention of 1911. This treaty was an attempt to curb the overfishing of seal in the North Pacific. It came into place after several years of conflict between fishing vessels from various countries, spurred by the scarcity of seals.

If humans could come up with such a treaty - Wynne-Edwards thought - would not animals also be able to construct similar conventions to avoid excessive consumption of resources? He argued that such conventions could also explain why animals were often not living on subsistence levels. He noted that on the fringes of a species' territory they 
often did. However, in the centers they were in good health - "and sometimes actually fat". Thus, he wanted to find a theory that did not depend on famine, predators, or diseases, but instead depended on social conventions within a territory, group, or species, that optimized the potential for long-term survival within the territory, or of the group or species.

Interestingly, it seems that he did not think of these conventions as being necessarily upheld by strictly altruistic behavior. Instead, he hypothesized that enforcement of population control would not depend on the parents in each case, but instead on other individuals in the group. By interpreting his theory in this way, group selection would not be needed, which was to become a general critique by Maynard Smith (1964). Instead it would suffice to say that when resources become scarce, then parents have an interest in killing other parent's offspring, which squares well with individual selection. On the other hand, Wynne-Edwards explicitly states that social conventions are based on group selection. He noted that group selection and individual selection might be in conflict, but then argued that group selection would always prevail. The reason, as he saw it, was that if it did not, then the species would go extinct.

\section{THE CONTROVERSY}

The group selection controversy broke out as a result of Wynne-Edwards (1962). Maynard Smith (1964) commented on a companion paper, Wynne-Edwards (1963), and dismissed Wynne-Edwards' theory. Maynard Smith argued that most of the observations that Wynne-Edwards claimed corroborated his theory in fact could just as easily, if not more easily, be explained by individual selection. However, he also went ahead and constructed a mathematical model as to how group selection could work. This model became known as the Haystack model.

The model consists of a field with haystacks. A pregnant mouse is placed under each haystack as it is created. The mice then procreate in the haystacks without any migration between them. In the end of each period the haystacks are collected, and the mice are put into one common population. New haystacks are then constructed and a new pregnant mouse, drawn from the new population, is placed under each. The mice can be of two types; aggressive mice, $A$, who breeds at the same rate irrespectively of the group size; and timid mice, $a$, who stop breeding when the group reaches a certain size.

Groups starting off with only aggressive mice will eventually run out of resources and will have a period of starving. However, Maynard Smith excludes the possibility that the mice actually go extinct. In groups with both aggressive and timid mice, both breed at the same rate until the population reaches the timid mice's limit. At this limit, the timid mice stop breeding and the aggressive mice take over the group completely. Since their resource management has been slightly better than the group with only aggressive mice, starving starts later in these groups. Finally, in groups that start off with only timid mice, they breed optimally and avoid starving towards the end of the period.

Thus, the model has some features that stand out. First, as already noted, aggressive mice breed aggressively enough to starve, but not aggressively enough to go extinct, which already Wynne-Edwards' noted in his comment to the paper. Second, 
in mixed groups the timid mice go completely extinct. This feature may be a shortcut to illustrate that the period under the haystack is very long, or at least sufficiently long for suboptimal strategies to be crowded out.

Thus, since groups of aggressive mice do not go extinct, and since timid mice in mixed groups go extinct, the model is biased against timid mice. Nevertheless, the result is that if only isolation is long enough, then the ratio of timid mice in the population will increase. The reason being that groups with only timid mice will grow very large. However, the general feeling among readers was that these long periods of absolute isolation were unrealistic, at least if this type of group selection should be a feature with wide applicability.

A further blow to the group selection argument was Williams (1966). Williams elaborated on Maynard Smith's argument that most of the phenomena ascribed to group selection could be explained by individual selection. Just like Maynard Smith, Williams did not reject group selection flat out, but insisted that the limited possibility of finding phenomena that group selection, but not individual selection could explain, suggested that it was a very weak force.

Williams argued that natural selection required a certain stability among the entities being selected for. Genes, for example, are fairly stable. There might be mutations, but overall they are fairly rare. Groups, on the other hand, are in constant flux, primarily due to migration. Furthermore, an individuals is fairly short-lived, while groups have longer time-spans. This also limits the possibility of more fit groups to replace less fit ones.

In sum, the papers by Maynard Smith and Williams were very influential. They effectively dismissed group selection in the form advanced by Carr-Saunders and WynneEdwards. Maynard Smith's Haystack model also for a long time became the benchmark group selection model.

\section{FiXATION}

The contributions of Wright (1945), and Maynard Smith (1964) stressed the importance of fixation, i.e. pure groups, for group selection to have any effect. The underlying idea is that mixed groups will degenerate over time. Pure groups are thus needed for cooperators to survive and eventually thrive. Wright thought of these pure groups coming into existence through drift, while Maynard Smith thought of them coming into existence when groups were formed.

Eshel (1972) extended the fixation approach to focus on migration. He confirmed Wright's conjecture that altruistic traits will dominate the population if migration is sufficiently low. Eshel also argued that an innovation that increases mobility would lead to less altruism.

Traulsen and Nowak (2006) provide a link between fixation models and the reproductive externality models treated later (also see Paulsson, 2002). They divide a population into groups and let the individuals in each group play an $n$-person prisoner's dilemma game. A single individual is chosen for reproduction with a probability proportional to its fitness. The offspring is put into the same group. When a group reaches the size $n$ two things can happen: With probability $q$ the group is split into two groups and another group is eliminated. With probability $1-q$ the group is not 
split up. Instead a randomly selected individual in the group is eliminated.

The fact that the group can split in two only after it has reached the size $n$ implies that the model is a reproductive externality model. However, to make it mathematically tractable, Traulsen and Nowak focus on the special case when $q$ is very small, instead stressing the fixation effect. The authors analytically show that the smaller the group size and the more numerous the groups, the higher will the probability be that altruists will dominate the entire population.

Traulsen and Nowak then substantially extend Wright's model. They show that the probability that altruists will dominate the population increases with $q$. The reason is that as $q$ increases it pays off relatively more to be in a group that has reached the size $n$, which groups with many altruists reach faster than other groups. In that sense the fixation result is an extreme result, giving a lower bound to the probability of altruists thriving in the population. Traulsen and Nowak also extend the model to include migration and multilevel selection. As in Wright (1945) and Maynard Smith (1964), increased migration makes it more difficult to sustain cooperation.

It is interesting to note that the fixation approach to group selection implies that somewhere in the human species' distant past there was a golden era for the evolution of social preferences. However, as mobility increased the circumstance under which altruism was created ceased to exist. This link between migration and the level of social preferences would be interesting to study empirically. Henrich et al (2005) studies the prosociality in 15 small-scale societies and compare the results with typical results among western students. They have no clear measure of migration, but find that smallscale societies typically give higher offers in the dictator game, whereas the offers in the ultimatum game are roughly the same as among western students.

\section{ASSORTATIVE GROUP FORMATION}

Wilson (1975) was the first to analyze how assortative group formation could lead to altruism being sustainable. While earlier models argued that isolation was a precondition for altruism to thrive, Wilson's model can instead be interpreted as a model were groups are reshuffled in every period. However, for altruists to survive in such a model, being an altruist and being matched with an altruist should be correlated.

Wilson notes that this can be achieved through various venues. Group formation based on kin is one of them, but this is only a special case. In subsequent work, e.g. in Sober and Wilson (1998) and Wilson and Dugatkin (1997), the author has discussed various structures that can result in assortative group formation.

Here we will discuss two mechanisms through which assortative groups may arise. First we will discuss the possibility of there being a conformist bias in imitation. Second we will discuss signalling.

6.1. Conformist bias. Experiments in social psychology has established that there seems to be a tendency for individuals to conform to other individuals' opinions (see Aronson et al, 2007; DeLamater and Myers, 2007). Such conformity can be of two types. It can be an informative influence in the sense that other individuals' opinions may reveal useful information. It can also be a normative influence in the sense that individuals may attach an intrinsic value to conforming. 
If the conformist bias is important, then it would lead to a fairly strong positive correlation between cooperating and being in groups that cooperate, and would thus be an very interesting avenue towards explaining assortative group formation. However, this raises the question of whether being a conformist is evolutionarily viable or not. Henrich and Boyd (2001) states that conformist transmission amounts to "using the popularity of a choice as an indirect measure of its worth". This would thus amount to informative conformism discounted by the risk of the measure being incorrect, and would imply that being a conformist is evolutionarily viable. Thus, the challenge for models of conformist transmission is not only to show that it can lead to higher cooperation, but also that being a conformist is evolutionarily viable.

Boyd and Richerson (1985) argued that individuals using an imitation rule with a conformist bias will be selected for. The reason, as they saw it, is that once a majority in the population has adopted a new and better behavior, then it is better to imitate that majority rather than to use an unbiased imitation rule.

Henrich and Boyd (1998) considered both individual learning and social learning. That is, individuals either learn by themselves, or learn from somebody else. When learning from somebody else, Henrich and Boyd assumed that individuals could either use an unbiased random rule or a conformist rule. They compared these two rules in a computer simulation, and found that the conformist rule would survive if the environment did not change too often. The logic behind this result seems to be that individual learning is better than social learning if a new and better technology is only used by a small fraction of the population. However, this is also when a conformist bias would perform badly compared to an unbiased imitation rule. Thus a conformist bias is not really better than no bias per se. It is simply that in situations when no bias are better than conformity, then social learning itself will not be successful. (See Wakano and Aoki, 2007; Nakahashi, 2007, for a fuller treatment of Henrich and Boyd, 1998).

In essence, a conformist rule is better than an unbiased rule if a majority uses the best strategy. Then individuals using the conformist rule will shift over to the best strategy faster than individuals using an unbiased rule. However, the converse is also true. If the majority uses a bad strategy, then individuals using the conformist rule will shift to the best strategy slower than individuals using an unbiased rule. Eriksson et al (2007) modified Henrich and Boyd's model to prolong the period when a new and better technology is used by a minority. As a result, a conformist bias seems never to be an evolutionarily stable strategy - although it seemed to be under some parameter values in Henrich and Boyd's setting.

The idea of a conformist bias being the crucial mechanism to uphold altruism is an interesting one. In particular its proponents have noted that it may serve to favor cooperation also in very large groups. However, as noted above, although conformism may lead to cooperation, it is may also be costly for the conformist. Thus, if we invoke exogenous conformity then we somewhat push the problem with defectors outside the model. Henrich and Boyd (2001) have attempted to somewhat address this issue. They consider a Prisoner's dilemma augmented by $i$ stages of punishments. I.e. in the first stage those that did not cooperate in the Prisoner's dilemma are punished. In all stages after the first, people who did not punish in the previous stage are punished. The payoff difference between a payoff biased rule and a conformity biased rule decreases for every 
stage. Eventually, in stage $i$, if everybody has at least some conformity in them, this will outweigh the urge to consider the payoff, and everybody will conform - and punish. Since everybody punishes in stage $i$, everybody will also punish in stage $i-1$. The backward induction is not perfect though. If there are sufficiently large benefits from defection, then everybody will still defect in the Prisoner's dilemma. Nevertheless, if these gains are not large enough, then cooperation will be sustained. The result is that the game has two Nash equilibria, one with defection and no punishment, and the other with cooperation and punishment to the $i^{\text {th }}$ level. Adding group selection to the model, the authors argue that the last equilibrium would be chosen.

Guzmán et al (2007) perform simulations to compare an imitation rule with a payoff bias with an imitation rule with a conformist bias. Individuals are only allowed to imitate other individuals within their own group. This means that the group selection effect disappears completely for payoff imitating individuals, who will never cooperate. Conformity imitating individuals, on the other hand, will sometimes end up in groups with many cooperators, and will then reap the group selection benefits through their imitating rule. The crucial mechanism in Guzmán et al is thus that individuals with a payoff bias will only imitate other group members. Thus, the players in this model seem to have fairly limited cognitive abilities. It would be interesting to let the players mental abilities grow, so that they also can imitate other players outside their own group. It seems likely that then a payoff bias would be favored instead of a conformist bias, suggesting that this type of conformity may have been an advantage early in human development, but since then has become a liability.

Richerson and Boyd (2005) argue that culture would tend to favor a conformist rule. Nevertheless, it seems that a conformist biased rule does not seem to be particularly conducive to technological innovations compared to a payoff biased rule. The incentives to innovate will be lower, as will the possibilities to spread new innovations. It is only after an innovation has been made, and after a majority has accepted it, that a conformist bias will perform as well as a payoff biased imitation rule. Thus, it could indeed be the case that a conformist bias is particularly ill suited for a species where innovations play such an important role as for humans. In addition, to the extent that new and better technologies make groups more successful, it seems that group selection itself would favor a payoff biased rule rather than a conformist biased rule.

6.2. Signalling. Another approach towards assortative group formation is to consider signalling before groups are formed. To my knowledge a formal analysis of such a game has not been made. (See Gintis et al, 2001, for a model where providing a public good is a costly signal). However, Grégoire and Robson (2003) analyze a somewhat similar game. They add the possibility of sending a costly signal before playing a Prisoner's Dilemma, and then add a group structure to the game.

The problem with signalling before playing a prisoner's dilemma, is of course that individuals will be prone to lie. A signal is not a commitment. Even if it is a costly signal, it will be subgame perfect to deviate from it. To make it possible to avoid being taken advantage off by the defectors, Grégoire and Robson allows for a strategy called the secret handshake. The secret handshake, also called the green beard effect (see e.g. Hamilton, 1964; Keller and Ross, 1998) and somewhat related to tag based 
models, (see e.g. Masuda and Ohtsuki, 2007) is a promise to cooperate that is only understood by other secret handshakers. In addition, somebody who plays the secret handshake will indeed cooperate when the game is played. The authors also allow for a strategy that takes advantage of secret handshakers. This strategy is called the sucker punch. Somebody who plays the sucker punch sends the secret handshake signal, but then deviates when the game is played.

The authors start off with a one-population game. Each player plays a round robin and gets the average payoff. All players then imitate the strategy that earns the highest payoff. Thus, if the entire population is playing defect without a signal, then the population can be invaded by two secret handshake players. The reason is that the secret handshakers will cooperate when playing with each other, but defect when playing with everybody else. The defectors, on the other hand, will always defect. The secret handshakers will thus earn a higher payoff than the defectors, and take over the population. However, this makes it possible for one sucker punch player to invade the population. Finally, when the population is dominated by sucker punch players, then one non-signaling defector may invade the population. As these defectors take over the population, it again becomes possible for two secret handshake players to invade it. Given that the secret handshake needs two mutations to invade a population, while both the sucker punch and the non-signalling defectors only need one mutation, the population will most of the time consist of defectors.

The authors then add a group structure to the model. Players are first playing within the group. They play against all other players in the group and receive the average payoff. All players in each group then imitate the highest yielding strategy in that group. Players are then playing a second round, again within the group, but now they instead imitate the highest yielding strategy in the entire population. Thus, if at least one group happens to be in a cooperative state, then the entire population will switch to that state. As a result, Grégoire and Robson (2003) show that if there are at least three groups, then all stochastically stable states involve cooperation.

To see this, suppose that the entire population is defecting, without sending any signals. A mutation to two secret handshakers within a group would then transform that group into secret handshakers and then transform the entire population to secret handshakers. To leave this state it is required that each group has a simultaneously mutation to at least one sucker puncher. Naturally, the more groups there are, the less likely is this to happen.

Although the signal is made after groups are formed, it seems that the logic of Grégoire and Robson (2003) would translate also into a setting where individuals first signal, then are put into groups, and finally play a Prisoner's Dilemma. In fact, then it seems it would suffice with two mutations to secret handshakers in the entire population - as opposed to within the same group - to transform first one group and then the entire population into secret handshakers. Such a population would be difficult to invade for sucker punchers though. A sucker puncher would transform his group into sucker punchers, but that group would then be transformed back to secret handshakers in the group stage. Thus, for sucker punchers to take over the population there must first be sufficiently many mutations to sucker punchers, and then at least one would have to end up in each group. To my knowledge such a variant of Grégoire and Robson's model 
has not yet been explored formally.

An example of signalling that seems to be at work both at the group formation stage and at the strategy selection stage is quorum sensing. This phenomenon has been observed especially in bacteria, but also in some social insects. Bacteria that use quorum sensing secrete a signalling substance as a function of how much of the substance it can sense in its vicinity. This can create a feed-back loop attracting and inducing ever more bacteria to secrete the substance. At a certain threshold, the bacteria can sense that they are in sufficient numbers to achieve a certain effect, e.g. bioluminescence, and can then trigger the necessary behavior to achieve that effect. ${ }^{2}$ The phenomenon has been quite thoroughly empirically studied, but at this point it is not certain whether it is altruistic or if group selection is involved. (See Joint et al, 2007, for a full issue of Philosophical Transactions B dedicated to quorum sensing).

\section{ReProductive EXTERNALITIES}

Many activities create externalities for others. That is, an organism's behavior will affect also other organisms' fitness, without this effect on others affecting the first organism's fitness. In economics this is called an externality. Externalities can be internalized through different avenues. In some cases, such as air pollution, extended property rights - i.e. rights to pollute - makes this possible. In other cases, such as defense or public roads, a central authority can at least partially ensure that such public goods are provided. In other cases, although much less explored, competition between companies may lead to higher efficiency within each company (Boyer, 1992; Vega Redondo, 1993; Sjöström and Weitzman, 1996; Weibull, 2000). In biology, a natural way to internalize externalities is through group selection. Groups that provide the public good will be more successful than others, which will lead to provision of that public good to spread. Weibull and Salomonsson (2006) call externalities relevant for organisms' fitness reproductive externalities. (In biology the term by-product has sometimes been used to describe externalities, see e.g. Connor, 1995; Leimar and Connor, 2003).

Several group selection papers have implicitly used reproductive externalities. Typically, as in Canals and Vega-Redondo (1998), Vega-Redondo (1996), and Traulsen and Nowak (2006), a group is disbanded at some exogenous probability, and high-yielding groups then have a possibility to colonize the disbanded group's niche or territory. Being a high-yield group is thus a public good. To the extent that they affect the provision of this public good, individual behavior consequently have reproductive externalities and they can be at least partly internalized through group selection.

Canals and Vega-Redondo (1998) generalize the stochastic evolutionary model of Kandori, Mailath, and Rob (1993) into a group selection model. Individuals are subject both to individual selection and a small mutation rate. The individuals are divided into groups, and these groups are disbanded at some rate and replaced by new groups. The members in the new groups can either imitate strategies that earn the highest average payoff in the general population, or imitate the strategies in the group with the highest payoff. Any weight on the latter imitation rule is thus a weight on group selection.

\footnotetext{
${ }^{2} \mathrm{I}$ am gratful to Olof Leimar for the pointer.
} 
Canals and Vega-Redondo then look at Coordination Games, in particular Stag Hunt games discussed earlier. As Kandori, Mailath and Rob showed, there will be a mutation force within each group leading to the evolutionary process spending most of its time close to the risk dominant equilibrium. The strength of that mutation force will be very weak if the mutation rate is very small. In Kandori, Mailath and Rob's setting this does not matter. However, with Canals and Vega-Redondo's group structure there is a counter balancing force. Each time a group is disbanded a proportion of the new members will imitate the strategies played in the groups with the highest payoff. Letting the mutation rate go to zero, the authors show that group selection will be a much stronger force, and the system will spend most of its time at the Pareto dominant equilibrium, rather than at the risk dominant equilibrium.

The setup in Vega-Redondo (1996) is similar to Canals and Vega-Redondo (1998), ${ }^{3}$ but he only lets new group members imitate strategies from groups with the highest payoff. Furthermore, instead of considering a Coordination Game, a Prisoner's Dilemma is considered. As long as the mutation rate is sufficiently small, Vega-Redondo's model result in a stochastic process spending most of its time with all groups composed of cooperating individuals.

In similar models, Vega-Redondo (1993) and Sjöström and Weitzman (1996) discuss the effect of competition on firms' efficiency. Within companies, employees have an incentive to shirk. However, if they do so, then their companies run a larger risk of going bankrupt, implying unemployment for the staff. Vega-Redondo (1993) considers a stag hunt game, whereas Sjöström and Weitzman (1996) consider a prisoner's dilemma. In both cases the total outcome is that competition between firms hinders shirking within firms. In the setting of Sjöström and Weitzman (1996) a technical issue arises with a finite number of firms. Then it is possible that simultaneous degeneration across all firms lead to a long run degeneration of the entire population. However, they show that with an infinitesimal probability of exogenous mutations in favor of cooperation, this degenerative tendency will lead to the same qualitative results as with an infinite number of firms. Weibull (2000) considers managerial owners' trade-off between profit and effort under imperfect competition between firms. The result is that stiffer, i.e. less imperfect, competition leads to a higher effort from managerial owners, i.e. a higher internal efficiency.

Weibull and Salomonsson (2006) consider both positive and negative reproductive externalities. When externalities are positive, for example when a parent protects the group's young, they foster altruism. When they are negative, for example in competition for mates or food, they foster spite.

The model consists of a finite, but large population. Groups of two players are randomly, and non-assortatively, formed in every period. The group members play the game once and receive the material payoffs in terms of offspring. Survival of the offspring, or effective payoff, depends on a function $\phi$ that depends on both group member's material payoffs. This is thus the group selection element in the model. The group members and their surviving offspring is then returned to the population and

\footnotetext{
${ }^{3}$ The first version of Canals and Vega-Redondo (1998) was published in 1994 as a Universidad de Alicante working paper.
} 
a new round starts. The function $\phi$ can be specified to include both within group competition, fostering spite; and within group cooperation, fostering altruism.

Weibull and Salomonsson first consider symmetric $2 \times 2$-games, and then show that when breeding is cooperative, then some games that are Prisoner's Dilemma games in material payoffs are transformed to either Coordination Games, Hawk-Dove games or Efficient Dominance Solvable games in effective payoffs. As a result, an observer only looking at material payoffs would conclude that the players were altruistic, whereas he would conclude that they were selfish if he looked at effective payoffs. In contrast, when breeding is competitive, then some Coordination Games, some Hawk-Dove games, and some Efficient Dominance Solvable games are instead transformed to Prisoner's Dilemma games.

In a more general formulation, and taking into account both cooperative and competitive breeding, Weibull and Salomonsson derive social preferences reflecting both altruism and spite. The derived preferences qualitatively agree with those discussed in Fehr and Schmidt (1999) and Charness and Rabin (2002). They are, for example, consistent with costly punishment. Furthermore, they are also consistent with rejections of "unfair" offers that have been observed in ultimatum game experiments.

Herold (2004) constructs a model where costly punishment and rewarding may be fostered in a group selection model based on reproductive externalities. Technically, Herold's model is based on reproductive externalities since the players know the composition of their groups. Boyd et al (2003) have looked at a similar model using simulation methods.

There is a fairly large literature on costly, or altruistic, punishment. E.g. Boyd et al (2003) has argued that costly punishment is altruistic since it may serve to uphold cooperation. However, Dreber et al (2008) present experimental evidence suggesting that punishment rather triggers retaliations and that punishers earn less than others.

Since groups are reshuffled in every period, these social preferences will be robust to migration. In contrast to the fixation approach, the reproductive externalities approach does not hinge on groups being isolated for long periods of time. Nevertheless, Williams (1966) also argued that migration would result in all groups being so similar that selection between them would at best be a very weak force. This argument has been empirically refuted by Bowles (2006) who, based on genetic data from recent huntergatherer populations, argues that "genetic differences between early human groups are likely to have been great enough so that lethal intergroup competition could account for the evolution of altruism". In addition, one could argue that cultural traits may be robust to migration, which would imply that cultural group selection could still play an important role.

Instead social preferences based on reproductive externalities hinge on the existence of public goods. The existence of such goods have presumably varied extensively during history, but can also be assumed to vary across current societies. Thus, a cultural interpretation of the theory could be used to explain the variability of social preferences between societies, as studied by Henrich et al (2005). Note that, in contrast to the fixation approach, there is nothing in this approach that indicates that social preferences should deteriorate as migration increases. In fact, to the extent that an increase in migration coincides with more public goods, social preferences could in fact become 
even stronger. Interestingly, in the study by Henrich et al, it was found that in societies where payoffs to cooperation was high, the level of prosociality was also higher. This result is in line with social preferences being fostered in a cultural model of reproductive externalities.

The ability to internalize reproductive externalities will be smaller in larger groups. With that in mind, it may seem puzzling that we can observe cooperation within very large human groups. However, despite the fact that humans can be organized in very large groups, sociological studies typically report that humans have remarkably few close friends. McPherson et al (2006) reported that the average American in 2004 only had 2.08 close friends with whom to discuss important matters. Although the number was down from 2.94 in 1985, it is striking that this number is much smaller than the number of acquaintances that our brains are thought to be able to handle. Dunbar (1998) argues that our neocortical processing capacity limits the number of acquaintances we are able to keep track of to 150 individuals. It may be that by allowing for networks and hierarchies it would be possible to reconcile these apparent contradictions.

\section{Group Selection or Kin Selection}

The issue of whether group selection is a special case of kin selection has received a lot of attention in the most recent literature (see e.g. Grafen, 2007a, b; Lehman et al, 2007; van Veelen, 2009; Wild et al, 2009).

Lehmann et al (2007) write that "kin selection operates whenever interactions occur among genetic relatives, that is, among individuals who tend to share a more recent common ancestor than individuals sampled randomly from the whole population." This is a very broad definition which implies that all of Nowak's five mechanisms are kin selection as soon as the interaction is "among individuals who tend to share a more recent common ancestor than individuals sampled randomly from the whole population". For example, two siblings engaged in repeated interactions would always fall under kin selection and never under direct reciprocity. This definition thus makes it impossible to disentangle different effects from each other whenever relatives are engaged in an interaction.

The term inclusive fitness has come to be more general than kin selection. For example, Ricklefs and Miller (2001) define inclusive fitness as "the fitness of an individual plus the fitness of its relatives, weighted according to the coefficient of relatedness". In addition, Grafen (2007a) argues that relatedness should be understood as "genetic similarity, however caused, whether by common ancestry, assortation of genotypes or kin recognition". Thus, according to this definition, two individuals having a larger genetic similarity than the rest of the population, but not sharing the same ancestry in any higher degree than the rest of the population, should fall under inclusive fitness, but not under kin selection. Note that this definition excludes two individuals having a larger phenotypic similarity than the rest of the population, but different relevant genotypes.

An interesting pair of papers are Killingback et al (2006) and Grafen (2007a). Killingback et al (2006) allow for different group sizes and dispersion of individuals between groups. They consider a public goods game. In such a game individuals are 
asked to contribute to a common pool. The contributions are then multiplied by some factor and distributed equally among them. In addition, contributing is costly, which implies that the individuals want to be in groups with many contributors while not contributing themselves. In that sense the public goods game is a more general version of the Prisoner's Dilemma.

Killingback et al (2006) then run computer simulations when varying a few parameters. Of particular interest is the dispersion rate. It turns out that when the dispersion rate is fairly low, except when it is close to zero, then contributing appears to be evolutionarily stable. However, when the dispersion rate increases, then contributing eventually ceases to be evolutionarily stable. Killingback et al (2006) argue that the underlying mechanism is Simpson's paradox, whereas Grafen (2007a) argues that the underlying mechanism is kin selection. His argument is that when dispersion is fairly low, then many generations will live together in the same group, which will foster contributions based on kin selection

van Veelen (2009) categorizes group selection models nicely into strongly altruistic and weakly altruistic (see also Wilson, 1979, 1990; van Veelen and Hopfensitz, 2007), and argues that strongly altruistic group selection models requires assortative group formation, whereas group formation can be completely random in weakly altruistic group selection models. He also argues that assortative group formation models can be reduced to kin selection models whereas this is not true for completely random group formation models, such as group selection models based on reproductive externalities.

\section{CONCLUSiON}

Group selection has typically been used to address two issues: equilibrium selection and altruism. The equilibrium selection issue - illustrated by the Coordination Games - has never really been controversial. The recent literature has instead focused on more complex issues, like whether group selection can lead to the Pareto dominant equilibrium, instead of the risk dominant equilibrium, being stochastically stable. As Canals and Vega-Redondo (1998) have shown, that is indeed the case.

Group selection as an explanation of altruism - illustrated by the Prisoner's Dilemma games - has been more controversial. The first formal models by Wright (1945) and Maynard Smith (1964) argued that group selection could only promote altruism if pure groups of altruists were allowed to be isolated for long periods. However, since then group selection has also been found to work through assortative group formation and reproductive externalities.

Group selection based on assortative group formation begs the question of how assortion comes about. A strand of the literature has focused on a conformity bias in imitation which could create assortion, whereas signalling as a means of obtaining assorted groups seems to have been somewhat neglected. An interesting aspect with signalling is that the interpretation of signals will involve culture. E.g. different cultures may develop different signals for the same behavior.

Group selection based on reproductive externalities has been more successful. VegaRedondo (1996) has shown that group selection with reproductive externalities will make altruism viable, whereas Weibull and Salomonsson (2006) have shown that reproductive externalities can result in social preferences discussed by Fehr and Schmidt 
(1999) and Charness and Rabin (2002). In addition Bowles (2006) have shown empirically that genetic differences between early human groups seems to have been sufficient to foster altruism.

Much empirical work remains to be done. For example, it would be interesting to compare the predictions of the fixation approach to the approach of reproductive externalities. The fixation approach predicts that altruism will increase if migration decreases, while the reproductive externalities approach suggests that altruism will increase if the positive externalities increases - as long as they can be internalized through group selection. It would be interesting to see whether these predictions are borne out, and, if so, which approach has more explanatory value. This may also calm some fears that our societies' increased mobility will lead to less altruism, and thus eventually the demise of civilized society. If the increased mobility also creates more positive externalities that we can try to internalize, then it may in fact lead to more altruism rather than less.

\section{REFERENCES}

Antal, T., M. A. Nowak, and A. Traulsen (2009): "Strategy Abundance in 2x2 Games for Arbitrary Mutation Rates," Journal of Theoretical Biology, 257, 340-344.

Aronson, E., T. D. Wilson, And R. M. Akert (2007): Social Psychology. Pearson Education, Upper Saddle River, NJ, USA, 6 edn.

Aumann, R. J. (1959): "Acceptable Points in General Cooperative N-Person Games," in Contributions to the Theory of Games IV, ed. by R. D. Luce, and A. W. Tucker, Annals of Mathematics Study 40, pp. 287-324, Princeton NJ. Princeton University Press.

Bergstrom, T. C. (2002): "Evolution of Social Behavior: Individual and Group Selection," Journal of Economic Perspectives, 16, 67-88.

Bowles, S. (2006): "Group Competition, Reproductive Leveling, and the Evolution of Human Altruism," Science, 314, 1569-1572.

Boyd, R., H. Gintis, S. Bowles, and P. J. Richerson (2003): "The Evolution of Altruistic Punishment," PNAS, 100, 3531-3535.

Boyd, R., And P. J. Richerson (1985): Culture and the Evolutionary Process. University of Chicago Press, Chicago, USA.

Boyer, R., And A. OrléAn (1992): "How Do Conventions Evolve?," Journal of Evolutionary Economics, 2, 165-77.

Canals, J., and F. Vega-Redondo (1998): "Multi-Level Evolution in Population Games," International Journal of Game Theory, 27, 21-35.

Carr-Saunders, A. M. (1922): The Population Problem: A Study in Human Evolution. Oxford University Press. 
Charness, G., and M. Rabin (2002): "Understanding Social Preferences with Simple Tests," Quarterly Journal of Economics, 117, 817-869.

Connor, R. C. (1995): "The Benefits of Mutualism: A Conceptuel Framework," Biol. Rev., 70, 427-457.

Darwin, C. (1871): The Descent of Man and Selection in Relation to Sex. Murray, London.

Dawes, R. M., and R. H. Thaler (1988): “Anomalies: Cooperation," The Journal of Economic Perspectives, 2, 187-197.

Dawkins, R. (1976): The Selfish Gene. Oxford University Press.

DeLamater, J. D., And D. Myers (2007): Social Psychology. Thomson Wadsworth, Belmon, CA, USA, 6 edn.

Dreber, A., D. G. Rand, D. Fudenberg, and M. A. Nowak (2008): "Winner's Don't Punish," Nature, 452, 348-351.

Dugatkin, L. A. (2002): "Cooperation in Animals: An Evolutionary Overview," Biology and Philosophy, 17, 459-476.

Dunbar, R. (1998): Grooming, Gossip, and the Evolution of Language. Harvard University Press, Cambridge, MA, USA.

Ellison, G. (1993): "Learning, Local Interaction, and Coordination," Econometrica, 61, 1047-1071.

Ely, J. C. (2002): "Local Conventions," Advances in Theoretical Economics, 2.

Eriksson, K., M. Enquist, and S. Ghirlanda (2007): "Critical Points in Current Theory of Conformist Social Learning," Journal of Evolutionary Psychology, 5, 67-87.

EsheL, I. (1972): "On the Neighbor Effect and the Evolution of Altruistic Traits," Theoretical Population Biology, 3, 258-277.

Eshel, I., L. Samuelson, And A. Shaked (1998): "Altruists, Egoists, and Hooligans in a Local Interaction Model," The American Economic Review, 88, 157-179.

Fehr, E., And K. M. Schmidt (1999): "A Theory of Fairness, Competition, and Cooperation," The Quarterly Journal of Economics, 114, 817-868.

Friedman, J. (1971): "A Non-Cooperative Equilibrium for Supergames," Review of Economic Studies, 38, 1-12.

FudenberG, D., And E. Maskin (1986): "The Folk Theorems for Repeated Games with Discounting or with Incomplete Information," Econometrica, 54, 533-554.

Gintis, H., S. Bowles, R. Boyd, and E. Fehr (2003): "Explaining Altruistic Behavior in Humans," Evolution and human behavior, 24, 153-172. 
Grafen, A. (2007a): "Detecting Kin Selection at Work Using Inclusive Fitness," Proceedings of the Royal Society B, 274, 713-719.

Grafen, A. (2007b): "An Inclusive Fitness Analysis of Altruism on a Cyclical Network," Journal of evolutionary biology, 20, 2278-2283.

Grégoire, P., and A. Robson (2003): "Imitation, Group Selection and Cooperation," International Game Theory Review, 5(3), 229-247.

Guzmán, R. A., C. Rodríguez-Sickert, and R. Rowthorn (2007): "When in Rome, Do as the Romans Do: The Coevolution of Altruistic Punishment, Conformist Learning, and Cooperation," Evolution and Human Behavior, 28, 112-117.

Hamilton, W. D. (1964): "The Genetical Evolution of Social Behaviour I and II," Journal of Theoretical Biology, 7, 17-52.

Henrich, J. (2004): "Cultural Group Selection, Coevolutionary Processes and LargeScale Cooperation," Journal of Economic Behavior and Organization, 53, 3-35.

Henrich, J., and R. Boyd (1998): "The Evolution of Conformist Transmission and the Emergence of Between-Group Differences," Evolution and Human Behavior, 19, $215-241$.

79-89.

(2001): "Why People Punish Defectors," Journal of Theoretical Biology, 208,

Henrich, J., R. Boyd, S. Bowles, C. Camerer, E. Fehr, H. Gintis, R. MCElreath, M. Alvard, A. Barr, J. Ensminger, K. Hill, F. Gil-White, M. Gurven, F. Marlowe, J. Q. Patton, N. Smith, and D. Tracer (2005): "Economic Man" in Cross-Cultural Perspective: Behavioral Experiments in 15 Small-Scale Societies.," Behavioral and Brain Sciences, 28, 795-855.

Herold, F. (2004): "Carrot or Stick: The Evolution of Reciprocal Preferences in a Haystack Model," mimeo, University of Munich.

Joint, I., J. A. Downie, and P. Williams (2007): "Bacterial Conversations: Talking, Listening and Eavesdropping," Philosophical Transactions B, 362(1483), 11151249 .

Kandori, M., G. Mailath, and R. Rob (1993): "Learning, Mutations, and Long Run Equilibrium in Games," Econometrica, 61, 29-56.

Keller, L., and K. G. Ross (1998): "Selfish Genes: A Green Beard in the Red Fire Ant," Nature, 394, 573-575.

Killingback, T., J. Bieri, and T. Flatt (2006): "Evolution in Group-Structured Populations Can Resolve the Tragedy of the Commons," Proceedings of the royal society, 273, 1477-1481. 
Kuzmics, C. (2003): "Individual and Group Selection in Symmetric 2-Player Games," mimeo, J. L. Kellogg School of Management.

Ledyard, J. O. (1995): "Public Goods: A Survey of Experimental Research," in Handbook of Experimental Economics, ed. by J. H. Kagel, and A. E. Roth, pp. 111194. Princeton University Press, Princeton, New Jersey.

Lehmann, L., L. Keller, S. West, and D. Roze (2007): "Group Selection and Kin Selection: Two Concepts But One Process," PNAS, 104, 6736-6739.

Leimar, O., and R. C. Connor (2003): "By-Product Benefits, Reciprocity, and Pseudoreciprocity in Mutualism," in Genetic and Cultural Evolution of Cooperation, ed. by P. Hammerstein, pp. 203-222. MIT Press, Cambridge, MA.

Masuda, N., And H. OHtsuki (2007): "Tag-Based Indirect Reciprocity by Incomplete Social Information," Proceedings of Royal Society B, 274, 689-695.

Maynard Smith, J. (1964): "Group Selection and Kin Selection," Nature, 201, 11451147.

McPherson, M., L. Smith-Lovin, and M. E. Brashears (2006): "Social Isolation in America: Changes in Core Discussion Networks over Two Decades," America Sociological Review, 71, 353-375.

NAKahashi, W . (2007): "The Evolution of Conformist Transmission in Social Learning When the Environment Changes Periodically," Theoretical Population Biology, 72, $52-66$.

Nowak, M. A. (2006): "Five Rules for the Evolution of Cooperation," Science, 314, $1560-1563$.

Oechssler, J. (1997): "Decentralization and the Coordination Problem," Journal of Economic Behavior and Organization, 32, 119-135.

Ohtsuki, H., and M. A. Nowak (2006): "Evolutionary Games on Cycles," Proceedings of the Royal Society B, 273, 2249-2256.

Okasha, S. (2006): Evolution and the Levels of Selection. Oxford University Press, Oxford.

Paulsson, J. (2002): "Multilevel Selection on Plasmid Replication," Genetics, 161, $1373-1384$.

Richerson, P. J., And R. Boyd (2005): Not by Genes Alone: How Culture Transformed Human Evolution. The University of Chicago Press, Chicago and London.

Ricklefs, R. E., and G. L. Miller (2001): Ecology. Freeman, New York.

Rubinstein, A. (1979): "Equilibrium in Supergames with the Overtaking Criterion," Journal of Economic Theory, 21, 1-9. 
Sjöström, T., and M. L. Weitzman (1996): "Competition and The Evolution of Efficiency," Journal of Economic Behavior and Organization, 30, 25-43.

Sober, E., And D. S. Wilson (1998): Unto Others: The Evolution and Psychology of Unselfish Behavior. Harvard University Press, Cambridge, USA.

Traulsen, A., and M. NowaK (2006): "Evolution of Cooperation by Multilevel Selection," PNAS, 103, 10952-10955.

Trivers, R. L. (1971): "The Evolution of Reciprocal Altruism," Quarterly Review of Biology, 46, 35-57.

Veelen, M. V. (2009): "Group Selection, Kin Selection, Altruism and Cooperation: When Inclusive Fitness is Right and When It Can Be Wrong," Journal of Theoretical Biology, 259, 589-600.

Veelen, M. V., And A. Hopfensitz (2007): "In Love and War: Altruism, Norm Formation, and Two Different Types of Group Selection," Journal of Theoretical Biology, 249, 667-680.

Vega-Redondo, F. (1993): "Competition and Culture in an Evolutionary Process of Equilibrium Selection: A Simple Example," Games and Economic Behavior, 5, 618-631.

(1996): "Long-Run Cooperation in the One-Shot Prisoner's Dilemma: A Hierarchical Evolutionary Approach," Biosystems, 37, 39-47.

Wakano, J. Y., And K. Aoki (2007): "Do Social Learning and Conformist Bias Coevolve? Henrich and Boyd Revisited," Theoretical Population Biology, 72, 504512.

Weibull, J. W. (1995): Evolutionary Game Theory. MIT Press, Cambridge, USA. (2000): "Internal Efficiency and External Conditions," in Planning, Shortage, and Transformation: Essays in Honor of János Kornai, ed. by E. S. Maskin, and A. Simonovits, pp. 109-126. MIT Press, Cambridge Massachusetts.

Weibull, J. W., and M. Salomonsson (2006): "Natural Selection and Social Preferences," Journal of Theoretical Biology, 239, 79-92.

Wild, G., A. Gardner, And S. A. West (2009): "Adaptation and the Evolution of Parasite Virulence in a Connected World," Nature, 459, 983-986.

Williams, G. C. (1966): Adaptation and Natural Selection : A Critique of some Current Evolutionary Thought. Princeton, New Jersey.

Wilson, D. S. (1975): "A Theory of Group Selection," Proc. Nat. Acad. Sci. U.S.A., $72,143-146$. 
(1979): "Structured Demes and Train-Group Variation," American Naturalist, $113,606-610$.

(1990): "Weak Altruism, Strong Group Selection," Oikos, 59, 135-140.

Wilson, D. S., and L. A. Dugatkin (1997): "Group Selection and Assortative Interactions," The American Naturalist, 149, 336-351.

Wright, S. (1945): "Tempo and Mode in Evolution: A Critical Review," Ecology, 26, 415-419.

Wynne-Edwards, V. C. (1962): Animal Dispersion in Relation to Social Behaviour. Oliver and Boyd.

- (1963): "Intergroup Selection in the Evolution of Social Systems," Nature, 200, 623-626.

Young, P. (1993): "The Evolution of Conventions," Econometrica, 61, 57-84. 